\title{
Health Risk Assessment of Heavy Metals in Surface Water of the Lhasa River, China
}

\author{
Liu $\mathrm{He}^{1}$, Bai Gao ${ }^{1, *}$, Huanhuan $\mathrm{Qin}^{1}$, Junping Liu ${ }^{1}$, Xiaoyan Ding $^{2}$, Dhawan Sanjay ${ }^{3}$, and \\ Andre Dong ${ }^{3}$ \\ ${ }^{1}$ College of Water Resources and Environmental Engineering, East China University of Technology, \\ Nanchang 330013, China \\ ${ }^{2}$ Institute of Soil Science, Chinese Academy of Sciences, Nanjing 210008, China \\ ${ }^{3}$ The Second Geological Brigade of the Tibet Autonomous Region Geology and Mineral Exploration \\ and Development Bureau, Lhasa 850000, China
}

\begin{abstract}
This study was performed in Lhasa River Watershed to explore the contents of heavy metals in river water and assess the health risks. The test results show that the contents of arsenic (As), chromium $(\mathrm{Cr})$ and uranium (U) are relatively low, reaching the Class III of the "Environmental quality standards for surface water (GB3838-2002)". Health risk assessment demonstrates that the average total risk value is $1.79 \times 10^{-5} \mathrm{yr}^{-1}$, which is lower than the maximum acceptable level of $5.05 \times 10^{-5} \mathrm{yr}^{-1}$ recommended by USEPA. Moreover, the average value of radionuclide risk (U) is calculated to be $9.47 \times 10^{-9} \mathrm{yr}^{-1}$, which is five orders of magnitude lower than the standard value of $5.0 \times 10^{-4} \mathrm{yr}^{-1}$. Therefore, the river water in the study area causes no significant health risk to people.
\end{abstract}

\section{Introduction}

Rivers are of both ecological and economic significances to the society [1]. However, river waters are quite vulnerable to pollution because they are naturally open, easily accessible and substantially used in agricultural, industrial and municipal processes [2]. The Lhasa river, a major tributary of the middle section of Yarlung Zangbo River, originates from the southern foot of the Nyaiqentanglha Mountain. It plays a vital role in the socio economic development of Lhasa City [3]. As one of the important local water sources, water quality of the Lhasa River is directly related to the health of local people living the downstream watersheds [4]. Therefore, the study of the contents of heavy metals and potential health risk in Lhasa River Watershed would be necessary and important.

\footnotetext{
*Corresponding author: gaobai@ecit.cn
} 


\section{Materials and methods}

\subsection{Study area}

The Lhasa River, which drains an area of around $32,588 \mathrm{~km}^{2}$ within a scope of $90^{\circ} 05^{\prime} \mathrm{E}$ $93^{\circ} 20^{\prime} \mathrm{E}$ and $29^{\circ} 20^{\prime} \mathrm{N}-31^{\circ} 15^{\prime} \mathrm{N}$, is the largest anabranch in the middle reach of the Yarlung Zangbo River (Fig. 1). The river is approximately $551 \mathrm{~km}$ long and with a mean altitude of $5400 \mathrm{~m}$ (ranging from $3500 \mathrm{~m}$ to $7162 \mathrm{~m}$ ). The mean annual sunshine duration is $2973 \mathrm{~h} / \mathrm{yr}$. The mean annual temperature is -1.7 to $9.7^{\circ} \mathrm{C}$. The mean annual rainfall is $1217 \mathrm{~mm} / \mathrm{yr}$. The upper reaches of the Lhasa River are mainly pastoral areas with a small population. There are relatively more anthropogenic activities in the middle reaches, with a small amount of cultivated areas. The lower reaches are relatively densely populated areas with advanced agriculture.

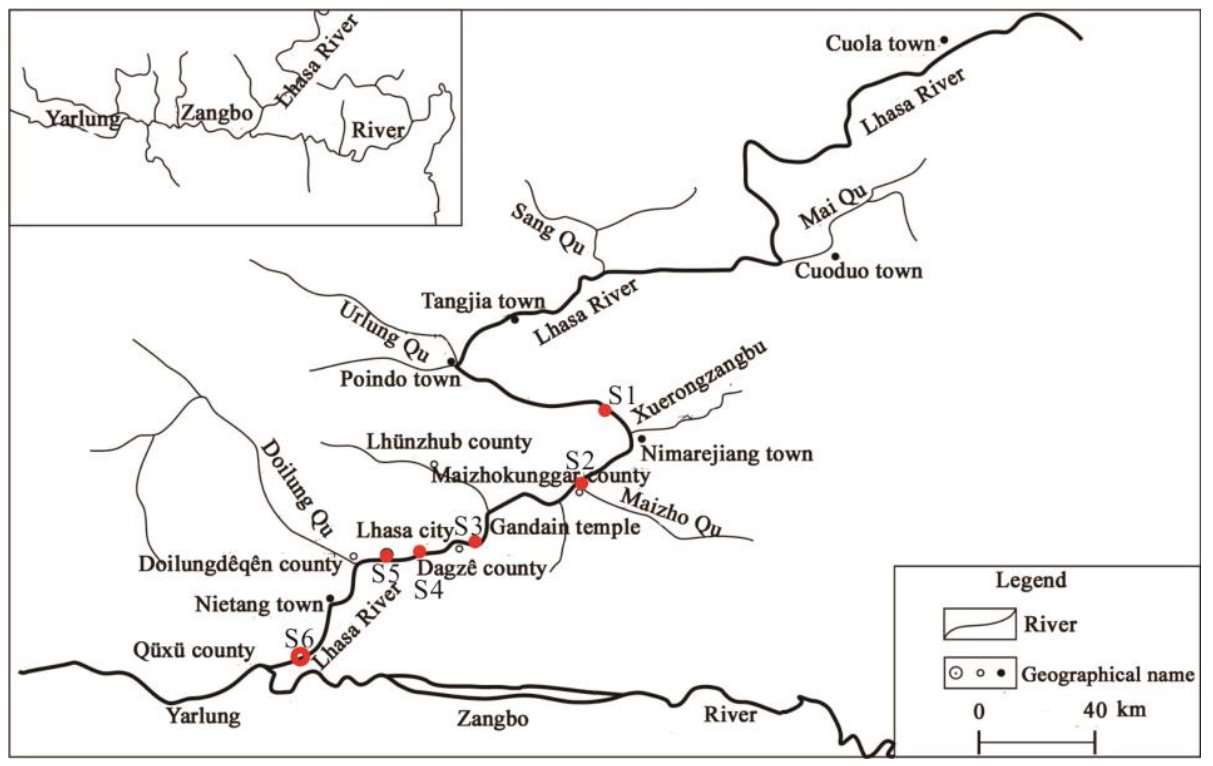

Fig.1. Location of the Lhasa River and the sampling sites

\subsection{Sampling sites and analytical methods}

The sampling activities were conducted in July 2017. A total of 6 samples were taken based on the river topography and residing places along the river (Fig. 1). Water samples were filtered through a $0.45 \mu \mathrm{m}$ Millipore filter in situ and delivered into a $500 \mathrm{~mL}$ polyethylene bottles. The samples were sealed until they were measured in the laboratory. Trace metals of As, $\mathrm{Cr}$ and $\mathrm{U}$ were analyzed by atomic absorption spectrometer (ICE3500, Thermo Fisher Scientific, USA). The contents of $U$ in water samples were detected by inductively coupled plasma optical emission spectrometer (ICP-OES, Thermo Fisher Scientific, USA).

\subsection{Health risk assessment}

Heavy metals are conveyed into human bodies via different ways, which lead to unequal influence on human health [5]. Chronic daily intake (CDI) is an index recommended by USEPA to estimate oral intake as follows: 


$$
C D I=D \cdot C_{i} / B W
$$

where $\mathrm{D}\left(\mathrm{L} \cdot \mathrm{d}^{-1}\right)$ represents average daily drinking water intake, and has a value of $2 \mathrm{~L} \cdot \mathrm{d}^{-1}$ as suggested; $C_{i}\left(\mu \mathrm{g} \cdot \mathrm{L}^{-1}\right)$ denotes the concentration of heavy metals; BW $(\mathrm{kg})$ is body weight and given to be $60 \mathrm{~kg}$.

As different types of chemicals bring different influences on human bodies, risk assessments of these chemicals can be characterized by non-carcinogenic risk (HI) and carcinogenic risk (RI).

The index of carcinogenic risk (RI) can be calculated by the following equation:

$$
R I=\left(C D I_{i} \cdot S F_{i}\right) / 76.5
$$

where $\mathrm{SF}_{\mathrm{i}}\left(\mathrm{kg} \cdot \mathrm{d} \cdot \mathrm{mg}^{-1}\right)$ is the slope factor of a carcinogen; $\mathrm{SF}_{\mathrm{As}}=15 \mathrm{~kg} \cdot \mathrm{d} \cdot \mathrm{mg}^{-1} ; \mathrm{SF}_{\mathrm{Cr}}=41$ $\mathrm{kg} \cdot \mathrm{d} \cdot \mathrm{mg}^{-1} ; 76.5$ is the average life expectancy based on the statistic recommended by WHO; $\mathrm{CDI}_{\mathrm{i}}$ represents the different index recommended by USEPA to estimate oral intake.

The carcinogenic risk of radionuclide (AI) can be calculated by the following equation:

$$
A I=1.25 \times 10^{-2} \cdot C \cdot D \cdot g_{g}
$$

where $\mathrm{C}\left(\mathrm{Bq} \cdot \mathrm{L}^{-1}\right)$ and $\mathrm{g}_{\mathrm{g}}\left(\mathrm{Sv} \cdot \mathrm{Bq}^{-1}\right)$ represent the concentrations of $\mathrm{U}\left(\mathrm{g}_{\mathrm{g}}=6.50 \times 10^{-8} \mathrm{~Sv} \cdot \mathrm{Bq}^{-1}\right)$ and intake dose conversion factor, respectively.

\section{Results and discussion}

\subsection{Water characteristics}

The analysis results of heavy metals and radionuclides in the river water are shown in Table 1. Three heavy metals, namely $\mathrm{As}, \mathrm{Cr}$ and $\mathrm{U}$, are detectable. Belonging to carcinogenic elements, As ranges from 1.95 to $4 \mu \mathrm{g} \cdot \mathrm{L}^{-1}$, with an average of $2.46 \mu \mathrm{g} \cdot \mathrm{L}^{-1}$, and Cr ranges from 0.082 to $0.134 \mu \mathrm{g} \cdot \mathrm{L}^{-1}$, with an average of $0.1 \mu \mathrm{g} \cdot \mathrm{L}^{-1}$. The heavy metals in Lhasa River are subject to Class III of the "Environmental quality standards for surface water (GB3838-2002)". The obtained heavy metal concentrations do not exceed the Class III standard as presented in Table 1. However, the concentration of $U$ ranges from 0.56 to $2.53 \mu \mathrm{g} \cdot \mathrm{L}^{-1}$, with an average of $1.3 \mu \mathrm{g} \cdot \mathrm{L}^{-1}$. The concentration of $\mathrm{U}$ at site $\mathrm{S} 6$ is higher than the values of other water samples, since this site is close to the downstream. This phenomenon has also been observed for heavy metals of As, which the value reaches the

\begin{tabular}{|c|c|c|c|c|c|c|c|}
\hline NO. & Longitude & Latitude & Elevation & As & $\mathrm{Cr}$ & $\mathrm{U}$ & County/District \\
\hline & & & $\mathrm{m}$ & \multicolumn{3}{|c|}{$\mu \mathrm{g} \cdot \mathrm{L}^{-1}$} & \\
\hline S1 & $30^{\circ} 04^{\prime} 38.475^{\prime \prime}$ & $91^{\circ} 43^{\prime} 42.652^{\prime \prime}$ & 3929 & 1.95 & 0.085 & 1.85 & Dagzê \\
\hline S2 & $29^{\circ} 50^{\prime} 45.082^{\prime \prime}$ & $91^{\circ} 44^{\prime} 05.800^{\prime \prime}$ & 3812 & 2.53 & 0.108 & 0.56 & Maizhokunggar \\
\hline S3 & $29^{\circ} 40^{\prime} 24.764^{\prime \prime}$ & $91^{\circ} 23^{\prime} 06.310^{\prime \prime}$ & 3700 & 2.23 & 0.134 & 1.00 & Dagzê \\
\hline S4 & $29^{\circ} 38^{\prime} 51.072^{\prime \prime}$ & $91^{\circ} 11^{\prime} 10.381^{\prime \prime}$ & 3661 & 2.06 & 0.108 & 1.09 & Lhasa \\
\hline S5 & $29^{\circ} 38^{\prime} 21.802^{\prime \prime}$ & $91^{\circ} 04^{\prime} 59.524^{\prime \prime}$ & 3646 & 2.01 & 0.098 & 0.75 & Lhasa \\
\hline S6 & $29^{\circ} 16^{\prime} 48.498^{\prime \prime}$ & $90^{\circ} 49^{\prime} 33.429^{\prime \prime}$ & 3578 & 4.00 & 0.082 & 2.53 & Konggar \\
\hline Average & & & & 2.46 & 0.100 & 1.30 & \\
\hline $\begin{array}{c}\text { Surface water } \\
\text { quality } \\
\text { standard III }\end{array}$ & & & & 50 & 50 & 50 & \\
\hline
\end{tabular}
maximum concertation at site 6 .

Table 1. Information of the sampling sites and the concentrations of heavy metals. 


\subsection{Health risk assessment}

Heavy metals, such as U, As and Cr, can cause serious organism depletion in some critical nutrients, and in turn enhance the occurrence of upper gastrointestinal cancer [6]. The health risks of heavy metals in Lhasa River are assessed and listed in Table 2. The average radionuclide risk is four orders of magnitude lower than the average total chemical risks $\left(5.68 \times 10^{-5} \mathrm{yr}^{-1}\right)$. The highest risk to human body in Lhasa River is ascribed to As, with the health risk ranging from $1.27 \times 10^{-5}$ to $2.61 \times 10^{-5} \mathrm{yr}^{-1}$. Cr is closely behind, which leads to an average risk of $1.83 \times 10^{-6} \mathrm{yr}^{-1}$ to local residents. The health risks of the heavy metals of $\mathrm{U}$ range from $4.09 \times 10^{-9}$ to $1.85 \times 10^{-8} \mathrm{yr}^{-1}$ (Table 2). Compared with the maximum acceptable level $\left(5.05 \times 10^{-5} \mathrm{yr}^{-1}\right)$ recommended by USEPA, the risks of As and $\mathrm{Cr}$ in Lhasa River are all below the maximum acceptable level. The health risks of $U$ are three to four orders of magnitude lower than the maximum acceptable level. The total chemical risk and the total risk of most sampling sites are all below the maximum acceptable level. The total chemical risk is close to the total risk, meanwhile the average radionuclide risk is obtained to be $9.47 \times 10^{-9} \mathrm{yr}^{-1}$ and is four orders of magnitude lower than the average total chemical risk. It is concluded that most potential health risks to human body in Lhasa River are caused by chemical carcinogens.

Table 2. Results of human health assessment for heavy metals $\left(\mathrm{yr}^{-1}\right)$.

\begin{tabular}{|c|c|c|c|c|c|}
\hline Sample ID & \multicolumn{2}{|c|}{ Chemical carcinogens (HI) } & $\begin{array}{c}\text { Total } \\
\text { chemical risk }\end{array}$ & $\begin{array}{c}\text { Radionuclide } \\
\text { carcinogen } \\
\text { (AI) }\end{array}$ & Total risk \\
\hline & As & $\mathrm{Cr}$ & & $\mathrm{U}$ & \\
\hline 1 & $1.27 \mathrm{E}-05$ & $1.52 \mathrm{E}-06$ & $1.43 \mathrm{E}-05$ & $1.35 \mathrm{E}-08$ & $1.43 \mathrm{E}-05$ \\
\hline 2 & $1.65 \mathrm{E}-05$ & $1.93 \mathrm{E}-06$ & $1.85 \mathrm{E}-05$ & $4.09 \mathrm{E}-09$ & $1.85 \mathrm{E}-05$ \\
\hline 3 & $1.46 \mathrm{E}-05$ & $2.39 \mathrm{E}-06$ & $1.70 \mathrm{E}-05$ & $7.31 \mathrm{E}-09$ & $1.70 \mathrm{E}-05$ \\
\hline 4 & $1.35 \mathrm{E}-05$ & $1.93 \mathrm{E}-06$ & $1.54 \mathrm{E}-05$ & $7.96 \mathrm{E}-09$ & $1.54 \mathrm{E}-05$ \\
\hline 5 & $1.31 \mathrm{E}-05$ & $1.75 \mathrm{E}-06$ & $1.49 \mathrm{E}-05$ & $5.48 \mathrm{E}-09$ & $1.49 \mathrm{E}-05$ \\
\hline 6 & $2.61 \mathrm{E}-05$ & $1.46 \mathrm{E}-06$ & $2.76 \mathrm{E}-05$ & $1.85 \mathrm{E}-08$ & $2.76 \mathrm{E}-05$ \\
\hline Average & $1.61 \mathrm{E}-05$ & $1.83 \mathrm{E}-06$ & $1.79 \mathrm{E}-05$ & $9.47 \mathrm{E}-09$ & $1.79 \mathrm{E}-05$ \\
\hline
\end{tabular}

\section{Conclusions}

The contents and health risk assessment of heavy metals in Lhasa River were evaluated in this study. The concentration of $\mathrm{U}$ at sites $\mathrm{S} 6$ is higher than the values of other water samples, since this site is located at downstream. The contents of As, $\mathrm{Cr}$ and $\mathrm{U}$ in all the water samples do not exceed Class III of the "Environmental quality standards for surface water (GB3838-2002)". All the obtained U concentrations in Lhasa River are lower than the maximum tolerance values (GB23727-2009). Meanwhile, health risk assessment shows that the average value of total risk ( $\mathrm{As}, \mathrm{Cr}$ and $\mathrm{U}$ ) is $1.79 \times 10^{-5} \mathrm{yr}^{-1}$, which is lower than the maximum acceptable level recommended by ICRP $\left(5.05 \times 10^{-5} \mathrm{yr}^{-1}\right)$. In addition, the value of 
radionuclide risk $(\mathrm{U})$ is $9.47 \times 10^{-9} \mathrm{yr}^{-1}$, which is lower than standard value $\left(5.0 \times 10^{-4} \mathrm{yr}^{-1}\right)$. The highest risk to human body in Lhasa River is ascribed to arsenic, with the health risk ranging from $1.27 \times 10^{-5}$ to $2.61 \times 10^{-5} \mathrm{yr}^{-1}$. Cr is closely behind, which leads to an average risk of $1.83 \times 10^{-6} \mathrm{yr}^{-1}$ to local residents. The health risks of the heavy metals of $U$ range from $4.09 \times 10^{-9}$ to $1.85 \times 10^{-8} \mathrm{yr}^{-1}$. The average values of the total risks are ranked in the order of $\mathrm{As}>\mathrm{Cr}>\mathrm{U}$. It is concluded that the river water in the study area causes no significant health risk to people.

Acknowledgements. This study was financially supported by Jiangxi Provincial Natural Science Foundation, China (The hydrogeochemical characteristics and environmental significance of the Lhasa River under the Influence of climate change and human activities).

\section{References}

1. W. Y. Chen, Landscape and Urban Planning, 157, 170-179 (2017)

2. Z. Li, X. Z. Mao, T. S. Li, S. Y. Zhang, Advances in Water Resources, 88, 68-79 (2016)

3. X.D. Lin, Y.L. Zhang, Z.H. Yao, et al. Geogr Sci, 18, 95-106 (2008) (in Chinese with English abstract)

4. F. Liu, Y. Liu, D.S. Jiang, et al. Ecotoxicology, 23, 567-576 (2014)

5. S. Muhammad, M. T. Shah, S. Khan, 98 (2), 334-343 (2011)

6. M. K. Türkdoğan, F. Kilicel, K. Kara, I. Tuncer, I. Uygan, Environmental Toxicology and Pharmacology, 13 (3), 175-179 (2003) 